\title{
ORIGINAL
}

Prof-1349

\section{ASSESSMENT OF SOCIO-ECONOMIC STATUS OF PATIENTS}

\section{DR. AYESHA ASHFAQ \\ MBBS, FCPS (Com. Medicine) \\ Associate Professor CHS,}

FMH College of Medicine \& Dentistry Lahore

DR. NOOR FATIMA, MBBS, FCPS (Com. Medicine) Associate Professor CHS, FMH College of Medicine \& Dentistry Lahore

\author{
DR. SEEMA DAUD, MBBS, FCPS (Com. Medicine) \\ Professor Community Medicine \\ Lahore Medical \& Dental College Lahore \\ Dr. Ahsen Nazir Ahmed, MBBS, FCPS (Surgery) \\ Additional Director, Accident \& Emergency, \\ Jinnah Hospital Lahore Pakistan.
}

\section{Dr. Zakariya Imam, MBBS, M.D}

Demonstrator, CHS,

FMH College of Medicine \& Dentistry Lahore

\section{Dr. Khayyam Shamshair, MBBS}

Demonstrator $\mathrm{CHS}$

FMH College of Medicine \& Dentistry Lahore

Dr. Salwa Hussain, MBBS

Demonstrator, CHS, FMH College of Medicine \& Dentistry Lahore

\begin{abstract}
Objective: To determine whether or not doctors assess the socio-economic status of their patients in order to customize treatment and improve compliance. Design: A cross-sectional Setting: Jinnah Hospital and Shalimar Hospital Lahore. Period: From March to June 2005 Methods \& Material: Ninety-three patients were included from each of the two randomly selected tertiary care hospitals (one public, one private) of Lahore. Doctor-patient encounters were observed. Results: No assessment was made for 134/186(72\%) patients. $51 / 186(27.4 \%)$ received an inadequate assessment. Only 01/186(0.5 \%) patient received a thorough assessment of his socioeconomic status. Doctors in the private hospital made better effort to assess the socioeconomic background of the patient (albeit inadequately), compared to those in the public hospital ( $p:<0.0001)$. Conclusion: Doctors should be regular and meticulous in patients' socioeconomic status assessment.
\end{abstract}

\section{INTRODUCTION}

Non-compliance with medication and follow-up regimens is a major public health problem and imposes a considerable financial burden on the health care system and the community ${ }^{1-2}$. This effect is multiplied in a developing country like Pakistan. Multiple factors such as age, gender, psychological stress, educational status and socioeconomic condition have been shown to be associated with patient non-compliance ${ }^{2-4}$. Although both lower and higher socioeconomic status have been shown 
to affect patient compliance in different settings, there is surprising lack of data on whether doctors actually assess such status in their patients. This study has been carried out to see whether doctors assess the socioeconomic status of their patients so as to be able to individualize their counseling and treatment choices and hence improve patient compliance.

\section{METHODS}

A cross-sectional study was conducted at general medical out-patient departments of Jinnah Hospital and Shalimar Hospital Lahore from March to June 2005. Approximately 2800 patients attended the medical OPDs in the two hospitals every month. Assuming a $50 \%$ prevalence rate, 93 patients were chosen from each hospital. Every tenth patient attending the general medical OPD was selected. Verbal consent was obtained from every patient. In case of refusal of consent, the next patient was approached for the study while sticking to the same interval to select the rest of the patients.

A trained data collector observed each doctor-patient interaction. It was noted whether doctors asked questions regarding occupation ${ }^{5}$, income and number of family members. Based on these three questions, the process of assessment of socioeconomic status was classified as being adequate, inadequate, or complete lack of assessment.

The doctors remained unaware of which patient interaction was being observed for this study. This procedure had been made clear to them while obtaining consent for their participation. The study had ethical approval from the Center for Health Research, Lahore. Data was entered and analyzed using SPSS version 12.0. Frequencies and two-sample t-test were calculated. A $p$ value of $<0.05$ was considered to be significant.

\section{RESULTS}

Overall, there were 138 females and 48 males (M:F=1: 2.8). $31 \%$ of the patients belonged to the $15-25$ year age group. No socioeconomic assessment was made in the case of $134 / 186(72 \%)$ patients. An inadequate assessment was made in 51/186 (27.4\%) patients. Only $1 / 186(0.5 \%)$ patient received a thorough assessment of his socioeconomic status. Individual results for the two hospitals are shown in Table I.

Table-I. Adequacy of assessment of socioeconomic status of patients at Jinnah and Shalimar Hospitals Lahore.

\begin{tabular}{|l|c|c|c|c|}
\hline \multirow{2}{*}{ SES Assessment } & Jinah Hosp Lahore & Shalimar Hosp Lhr & \multicolumn{2}{|c|}{ Two sample t-test } \\
\cline { 2 - 5 } & Frequency(\%) & Frequency(\%) & T statostoc n-1 (dt:184) & p value \\
\hline Assessed adequately & $1(1.1 \%)$ & - & 1.01 & $<.311$ \\
\hline Inadequately assessed & $5(5.4 \%)$ & $46(49.5 \%)$ & 6.73 & $<0.0001^{*}$ \\
\hline Not assessed at all & $87(93.5 \%)$ & $47(50.5 \%)$ & 6.53 & - \\
\hline Total & $93(100 \%)$ & $93(100 \%)$ & $-0001^{*}$ \\
\hline \multicolumn{2}{|c|}{${ }^{*}$ Results reach statistical significance } \\
\hline
\end{tabular}

\section{DISCUSSION}

Our study shows that in the majority of instances, doctors do not bother to perform a comprehensive assessment of the patients' socioeconomic status in spite of ample evidence that, if not taken into consideration, this factor can adversely affect patient compliance ${ }^{2-4}$. In fact, in many instances doctors do not perform such an assessment at all. Such an approach carries multiple risks since it means that doctors are unable to customtailor their treatment and even their counseling for every patient. That in turn can affect patient compliance and even the doctor-patient rapport, leading to serious consequences for a developing country like Pakistan ${ }^{1-2}$. Our study shows that doctors in Shalimar hospital (a 
private hospital) still make an effort to assess the socioeconomic background of the patient to an extent, but those at Jinnah hospital (a public hospital) do not even make that much an attempt.

There may be multiple reasons for these results. Firstly, doctors might simply assume the socioeconomic background by observation of the patient's appearance, conduct, behavior and conversation. Doctors in a public hospital may not even feel the need to make such an assessment, assuming that all patients attending a public hospital would belong to the lower socioeconomic background. On the other hand, private hospitals receive patients from diverse socioeconomic backgrounds and hence are more likely to resort to such an assessment. Furthermore, doctors in the private sector generally tend to spend more time with their patients and pay more attention to the concerns of the patients during the consultation.

\section{CONCLUSION}

We conclude that doctors should assess the socioeconomic status of each of their patients routinely and thoroughly so as to cater to individual counseling / treatment needs and hence improve patient compliance.

\section{REFERENCES}

1. Johnell K, Lindstrom M, Sundquist J, Eriksson C, Merlo J. Individual characteristics, area social participation, and primary non-concordance with medication: a multilevel analysis. BMC Public Health 2006;6:52

2. Wamala S, Merlo J, Bostrom G, Hogstedt C, Agren G Socioeconomic disadvantage and primary nonadherence with medication in Sweden. Int J Qual Health Care 2007;19:134-40.

3. Almas A, Hameed A, Ahmed B, Islam M. Compliance to antihypertensive therapy. J Coll Phys Surg Pak 2006;16:23-6.

4. Rizwan T, Khan S. A study of reasons of noncompliance to psychiatric treatment. J Ayub Med Coll Abbottabad 2005;17:26-8.

5. Furler J, Stewart A, Sims J, Naccarella L. Patient Social and Economic circumstances. GP perceptions and their influence on management. Aust Fam Physician 2005;34:198-92.

\section{THE MAN WHO HAS NO PROBLEM IS OUT OF THE GAME}

Elbert Hubbard 